\title{
Brain Abscesses Complicating Acute Pneumococcal Meningitis During Etanercept Therapy
}

\author{
Yusuf Kasirye, MD; Narendranath Epperla, MD; Janaki Ram Manne, MD; \\ Sowjanya Bapani, MD; and Romel J Garcia-Montilla, MD, PhD
}

\begin{abstract}
Brain abscess formation as a sequelae of community-acquired pneumococcal meningitis is extremely rare, accounting for less than I\% of all meningitis complications. Although metastatic seeding from a distal peripheral septic focus has been observed, this phenomenon most commonly occurs in the context of ear, nose and throat infections, post-cranial neurosurgical procedures, traumatic open cranial injury, or immunosuppression. We present the case of a man, 61 years old, on etanercept therapy for ankylosing spondylitis who developed multiple brain abscesses as a complication of pneumococcal meningitis. We believe that the predisposition to this extremely rare complication of a particularly aggressive pneumococcal meningitis was most likely due to the underlying immunosuppression resulting from etanercept therapy. As far as we know, this case is the first report linking multiple brain abscess formation in a patient with community-acquired pneumococcal meningitis with etanercept therapy.
\end{abstract}

Keywords: Brain abscess; Etanercept; Immunosuppression; Pneumococcal meningitis

Corresponding Author:

Yusuf Kasirye, MD

Department of Internal Medicine

Marshfield Clinic-Park Falls Center

50 Sherry Ave

Park Falls, WI 54552 USA

Tel: $7|5-762-73| 1$

Fax: 7/5-389-5757

Email: kasirye.yusuf@marshfieldclinic.org

Received: August 31, 2011

Revised: February 17, 2012

Accepted: February 22, 2012

doi: $10.3121 / \mathrm{cmr} .2012 .1049$
$A$

man, aged 61 years, on etanercept treatment for ankylosing spondylitis, presented to the emergency room with altered mental status. He had been discovered at his vacation cabin by emergency services after his family was unable to contact him. His past medical history was significant for systemic hypertension and tobacco abuse. He had no known allergies, nor any recent head trauma, splenectomy, immunodeficiency disorders, or history of alcoholism. He had been receiving etanercept $50 \mu \mathrm{g}$ subcutaneously every week on a continuous basis for the past 4 years. Other medications included acetaminophen, metoprolol, and omeprazol. His vaccinations were up to date, including a 23 -valent pneumococcal polysaccharide vaccine that had been given before starting etanercept.

The initial physical examination on arrival to the emergency room revealed an unresponsive male with a Glasgow coma scale of 6/15 (eye opening, 2; verbal response, 1; motor response, 3). His vitals signs included blood pressure 140/80 $\mathrm{mmHg}$, pulse 150 beats/minute, temperature $103^{\circ} \mathrm{F}$, respirations 50 breaths/ minute with stridor, and oxygen saturation of $82 \%$ on room air. The patient was also noted to have nuchal rigidity, left-sided hemiparesis, and facial drooping, as well as a positive Kerning's and Brudzinski's sign (more evident on the right side). The remainder of the physical examination, including ear canal and tympanum were unremarkable. The patient had a generalized seizure for which he received intravenous (IV) lorazepam and phenytoin. He was intubated for airway protection and admitted to the intensive care unit. An electrocardiogram 
Table 1. Significant laboratory findings.

\begin{tabular}{|c|c|c|}
\hline & Value at Admission & Normal Range \\
\hline \multicolumn{3}{|l|}{ Laboratory test } \\
\hline Leukocytes & $22.400 / \mathrm{mm}^{3}$ (30\% Bands) & $4.0-11,000 / \mathrm{mm}^{3}$ \\
\hline Hemoglobin & $14.0 \mathrm{~g} / \mathrm{dL}$ & $12.9-17.3 \mathrm{~g} / \mathrm{dL}$ \\
\hline Hematocrit & $42.2 \%$ & $38.0-51.0 \%$ \\
\hline Mean corpuscular volume & $93.3 \mathrm{fL}$ & $82.0-99.0 \mathrm{fL}$ \\
\hline Platelets & $112 \times 10^{3} / \mathrm{uL}$ & $150-400 \times 10^{3} / \mathrm{uL}$ \\
\hline Sodium & $133 \mathrm{mmol} / \mathrm{L}$ & $135-145 \mathrm{mmol} / \mathrm{L}$ \\
\hline Potassium & $3.5 \mathrm{mmol}$ & $3.5-5.5 \mathrm{mmol} / \mathrm{L}$ \\
\hline Blood urea nitrogen & $12 \mathrm{mg} / \mathrm{dL}$ & $6.0-24.0 \mathrm{mg} / \mathrm{dL}$ \\
\hline Creatinine & $0.7 \mathrm{mg} / \mathrm{dL}$ & $0.6-1.2 \mathrm{mg} / \mathrm{dL}$ \\
\hline Glucose & 200 mg/dL & $60-120 \mathrm{mg} / \mathrm{dL}$ \\
\hline C-Reactive protein & $22.3 \mathrm{mg} / \mathrm{dL}$ & $0.0-1.0 \mathrm{mg} / \mathrm{dL}$ \\
\hline INR & 1.0 & $0.9-1.1$ \\
\hline \multicolumn{3}{|l|}{ Cerebrospinal fluid analysis } \\
\hline Appearance & Turbid & - \\
\hline Gram stain & Gram positive cocci in pairs & - \\
\hline Total nucleated cells & $4050 / \mathrm{mm}^{3}$ (90\% neutrophils) & Less than 5 cells $/ \mathrm{mm}^{3}$ \\
\hline Glucose & $0 \mathrm{mg} / \mathrm{dL}$ & $40-70 \mathrm{mg} / \mathrm{dL}$ \\
\hline Total protein & $915 \mathrm{mg} / \mathrm{dL}$ & $15-45 \mathrm{mg} / \mathrm{dL}$ \\
\hline CSF culture & $\begin{array}{l}\text { Streptococcus pneumoniae } \\
\text { (penicillin sensitive) }\end{array}$ & - \\
\hline
\end{tabular}

was performed which showed only sinus tachycardia. An initial non-contrast-enhanced computerized tomography (CT) of the head was normal, as was a chest radiograph. Laboratory tests for human immunodeficiency virus (HIV), serum alcohol levels, and urine drug toxicology screen were all negative. Ammonia levels and liver function tests were also normal. Cerebrospinal fluid (CSF) analysis revealed; 4050 total nucleated cells $/ \mu \mathrm{L}$ (93\% neutrophils), glucose $0 \mathrm{mg} / \mathrm{dL}$, total protein $915 \mathrm{mg} / \mathrm{dL}$, and gram positive cocci in pairs. Other significant laboratory findings are shown in table 1. The patient was diagnosed with acute community-acquired bacterial meningitis. Ceftriaxone (2 g every 12 hours), ampicillin ( 2 g every 4 hours), vancomycin (1.2 g every 12 hours), and dexamethasone (10 mg every 6 hours) were started. Blood and CSF cultures later demonstrated a penicillin-sensitive pneumococcus (MIC $<0.03 \mu \mathrm{g} / \mathrm{mL}$ ). The organism was further identified by both optochin sensitivity testing in carbon dioxide incubation and pneumococcalspecific antibody testing. The antibiotic regimen was de-escalated to ceftriaxone monotherapy.

At 48 hours, short lasting convulsions were still observed, and a head CT showed a new small hemorrhage in the peripheral area of the right frontal lobe with surrounding edema, involving primarily the white matter, suggestive of cerebral ischemia (figure 1), although the possibility of cerebritis was also considered. The tympanic membranes, middle ears, and paranasal sinuses were reported as normal.
A contrast-enhanced magnetic resonance imaging (MRI) with diffuse weighted images (DWI) and fluid attenuated inverse

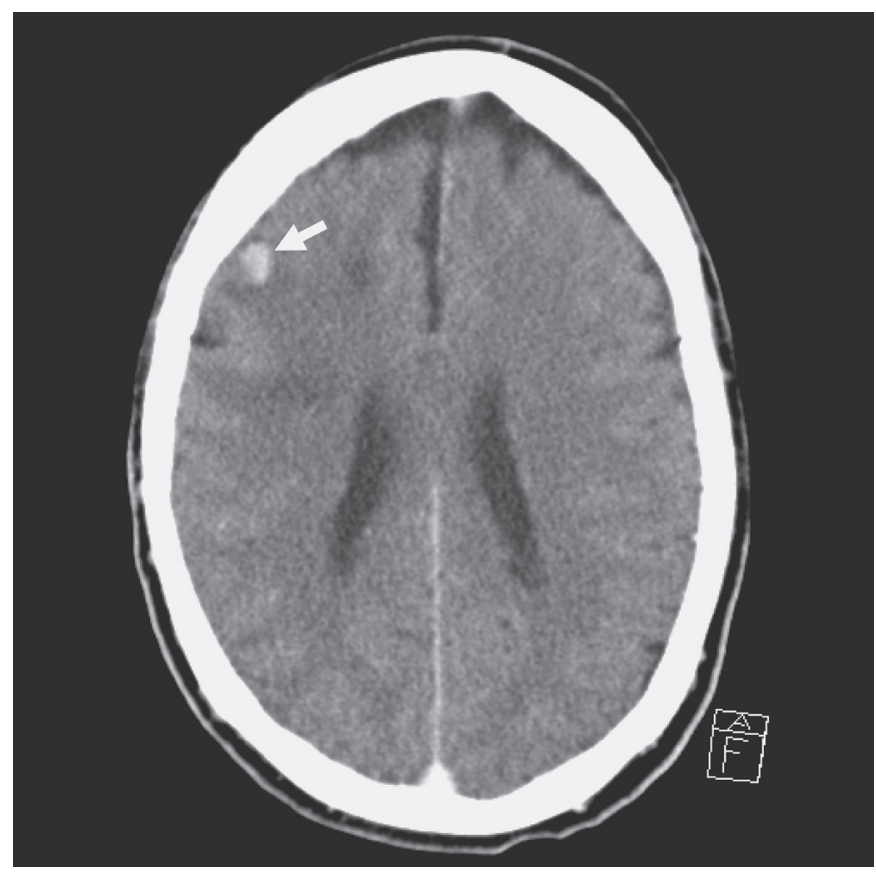

Figure 1. Computed tomography of the head without contrast done on day 2 of admission showing a focal hyper-dense image in the right frontal lobe parenchyma, consistent with intracerebral hemorrhage (see arrow) with surrounding edema. 


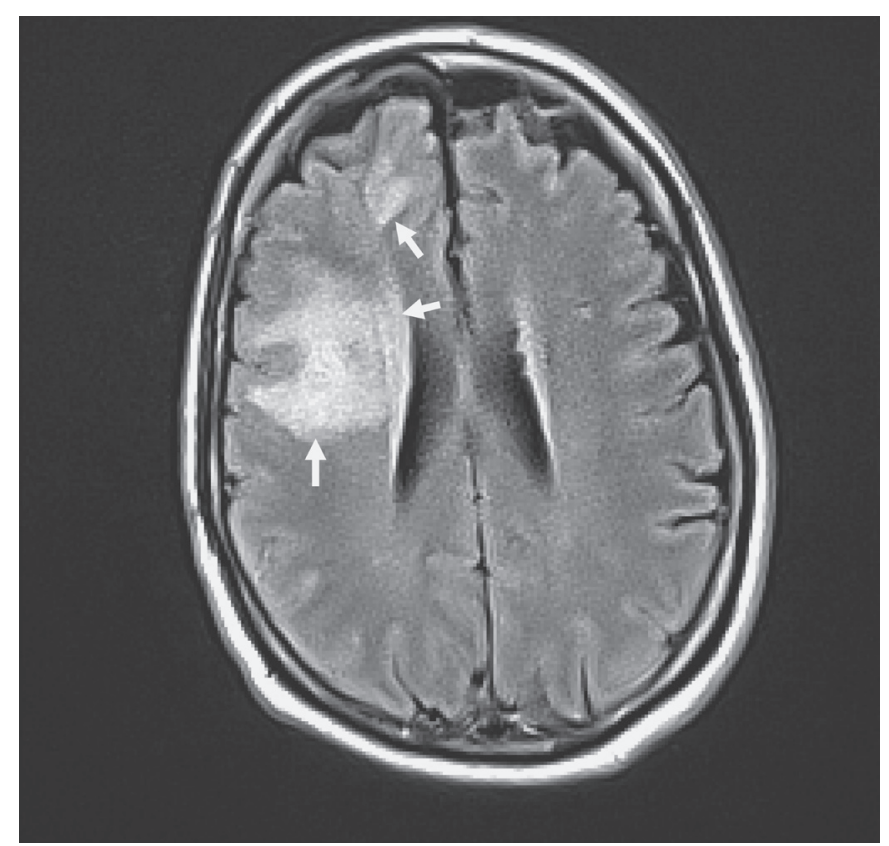

Figure 2. T2-weighted contrast-enhanced magnetic resonance imaging study showing increased signal intensity in the right frontal lobe and in the anterior periventricular areas consistent with cerebritis and ventriculitis (see arrows). Minimal mass effect is also noted.

recovery (FLAIR) techniques confirmed the diagnosis of cerebritis with ventriculitis without abscess formation and no evidence of vascular involvement (figure 2). Hemodynamic parameters were optimized, and the doses of anti-seizure medications were increased. On day 9, the patient's neurological status had improved enough to allow extubation and subsequent transfer to a general medical floor.

On day 13, some new subtle fluctuations in his mental status, characterized by short lasting periods of visual hallucinations and mild increased somnolence, with a significant peak elevation on the daily control of C-reactive protein (CRP) from $10 \mathrm{mg} / \mathrm{dL}$ to $28 \mathrm{mg} / \mathrm{dL}$, contributed to the decision to obtain a new contrast-enhanced head CT, which now revealed three new ring-enhancing lesions in the right frontal lobe, consistent with brain abscesses (figure 3). A neurosurgical consult was sought, but because of the multiplicity and size of the abscesses, as well as the minimal mass effect with only a small mid-line shift on the imaging studies, the patient was not considered a surgical candidate, and continuation of medical treatment with close clinical and imaging monitoring was recommended.

Based on the high penicillin sensitivity of the pneumococcus $(\mathrm{MIC}<0.03 \mathrm{mcg} / \mathrm{ml})$, the infectious disease service recommended changing the ceftriaxone monotherapy to penicillin continuous IV infusion at 18 million units/day. After the sixteenth day of treatment, the patient's CRP declined to $5.1 \mathrm{mg} / \mathrm{dL}$, and no further hallucinations, lethargy, or seizures were observed. He remained mildly disarthric with left-sided hemiparesis (predominantly in the lower extremity) and was transferred to the rehabilitation unit. $\mathrm{He}$ was discharged to home on antiseizure medications and orders to complete a total of 6 weeks of outpatient IV antibiotic therapy. A repeat contrast-enhanced CT done after completion of the antibiotic therapy demonstrated an almost complete resolution of the intracerebral lesions (figure 4). The patient achieved a full neurological recovery. A followup electroencephalogram was normal, so his anti-seizure medications were tapered off, and the etanercept therapy was discontinued.

\section{Discussion}

Etanercept is a recombinant receptor fusion protein that binds to tumor necrosis factor- $\alpha$ (TNF- $\alpha$ ), reducing its bioavailability. ${ }^{1}$ TNF- $\alpha$ is a cytokine that plays a critical role in the regulation of idiopathic, infectious, immunological, and inflammatory processes. Specifically during infections, TNF- $\alpha$ plays a key role in the function and coordination of monocytes, neutrophils, B-cells, and T-cells. It tends to confer a double-edged effect in disease processes as noted in either its excess or inhibited states. Excess TNF- $\alpha$ has also been linked to the etiology of neuroinflammatory ${ }^{2,3}$ and rheumatologic disorders, ${ }^{4}$ hence the use of anti-TNF- $\alpha$ antibodies as therapeutic agents in treating the latter disorders has become common. The role of anti-TNF- $\alpha$ agents in treatment of neuroinflammatory disorders is still developing, although there has been some promising data.

It is therefore not surprising that the neutralization of TNF- $\alpha$, through the use of anti-TNF- $\alpha$ therapy, can be associated with the development of fulminant forms of infectious diseases that might be difficult to treat. The spectrum of pathogens that

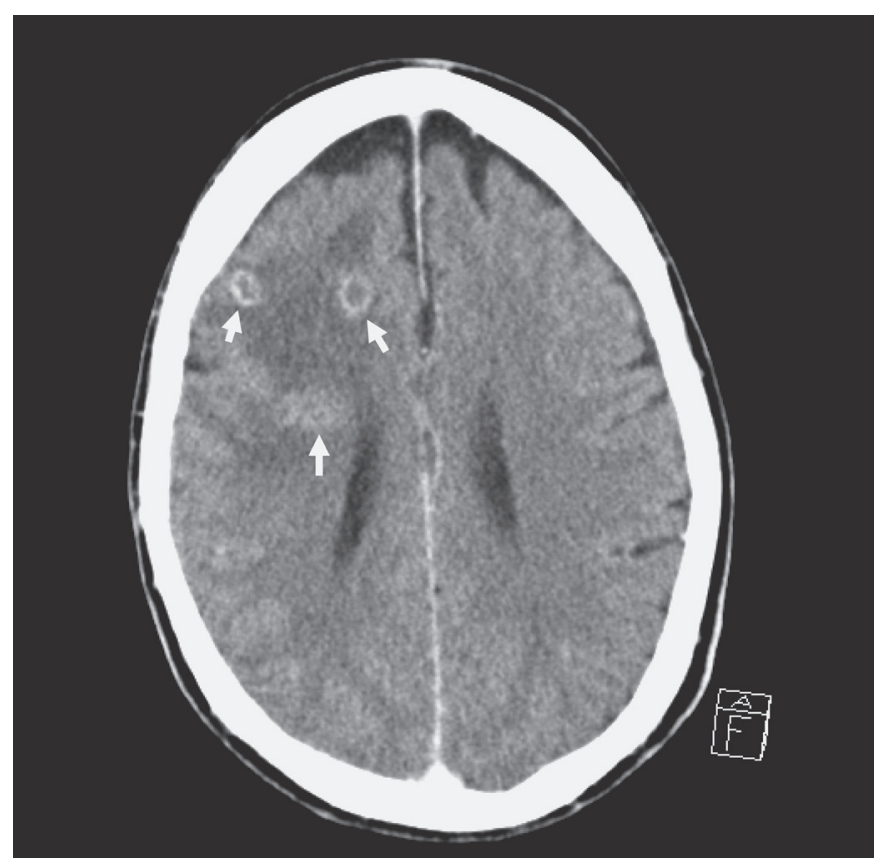

Figure 3. Contrast-enhanced computed tomography of the head done 14 days after admission showing 3 ring-enhancing lesions (see arrows) in the frontal lobe with low-density edema surrounding them. 


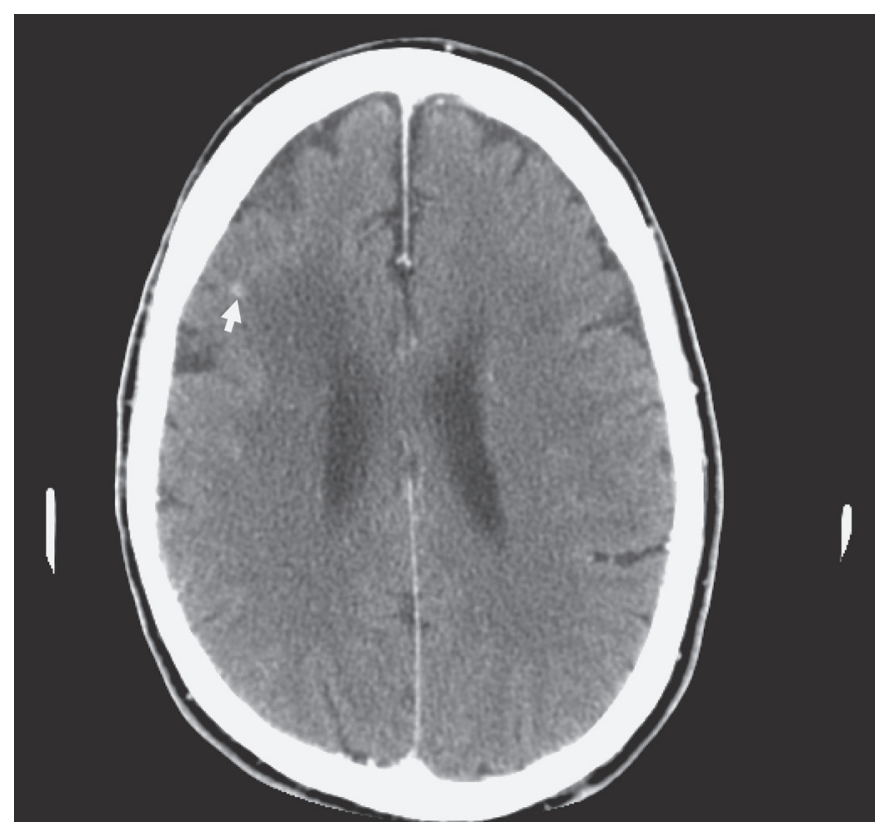

Figure 4. Contrast-enhanced computed tomography of the head done after 6 weeks of antibiotic treatment. The ringenhancing lesions evident on figure 3 have practically disappeared and now are seen as small focal areas of enhancement (see arrow). Associated low-density edema has also decreased.

can cause severe invasive disease in patients on anti-TNF- $\alpha$ medications ranges from common Gram-positive and Gramnegative bacteria to more opportunistic agents like Mycobacterium tuberculosis, Cryptococcus spp, and Aspergillus spp. The increased risk of disseminated tuberculosis or fulminant pyogenic infections (eg, uncontrolled pneumococcal necrotizing fasciitis) is attributed to the cellmediated immunity dysfunction and phagocytic dysfunction, respectively, associated with the use of this class of medications. ${ }^{5,6}$ Reported bacterial infections associated specifically with etanercept use have included pyelonephritis, bronchitis, septic arthritis, osteomyelitis, cellulitis, abscesses, necrotizing fasciitis, and septicemia. ${ }^{5-8}$ As far as we know, only one case of pneumococcal meningitis complicating a middle ear infection in a patient on etanercept therapy has been reported. ${ }^{9}$ To the best of our knowledge, our case is the first report in the literature describing a link between etanercept and community-acquired pneumococcal meningitis complicated with multiple brain abscess development.

The leading cause of acute community-acquired bacterial meningitis in adults remains Streptococcus pneumoniae. Despite effective antibiotic therapy, recent advances in adjunctive therapy (ie, dexamethasone) and modern supportive care facilities, the mortality rate remains as high as $20 \%$ to $30 \%$. Most fatalities are attributed to either intracranial complications (eg, hydrocephalus, cerebritis, ventriculitis, abscess, ischemic infarct, cerebral hemorrhage, septic sinus venous thrombosis) or systemic multi-organ failure in the context of sepsis, disseminated intravascular coagulation, or adult respiratory distress syndrome. ${ }^{10-12}$
The incidence of intracranial complications in patients with pneumococcal meningitis is higher in those patients who are immunosuppressed. They experience a more severe form of the disease, characterized by an increased incidence of comatose status, neurological deficits, and new onset of seizures, as well as a worse outcome than immunocompetent patients. ${ }^{10,11}$ In these immunocompromised cases, very close monitoring with laboratory tests (able to quantify the disease activity and its response to treatment) and serial brain imaging must be undertaken.

Brain abscesses remain an exceedingly rare complication in community-acquired pneumococcal meningitis, accounting for less that $1 \%$ of all the cerebral complications. ${ }^{10,11}$ Common predisposing factors are the same as those for meningitis, and include mastoiditis, otitis, sinusitis, pneumonia, and immunocompromised status, with the latter being defined in most large studies as the presence of asplenia, chronic debilitating disease (eg, diabetes), alcoholism, HIV infection, or use of immunosuppressive drugs (eg, anti-TNF- $\alpha$ agents). ${ }^{11-13}$

It is well accepted that patients with suspected acute meningitis and signs of space-occupying lesions, moderate to severe impairment of consciousness, or immunosuppression do benefit from cross-section brain imaging upon admission before proceeding with a lumbar puncture. Although this matter has been established for pre-admission patients, the timing and indications for repeating the cross-sectional brain imaging after the diagnosis of meningitis has been made remain unsubstantiated. Current clinical consensus is that a patient whose condition deteriorates, or who has previous abnormal findings, should have repeat imaging studies, although this decision is heavily reliant on the judgment of the clinician. ${ }^{14,15}$ The imaging modalities utilized are contrastenhanced CT or a contrast-enhanced MRI. ${ }^{16,17}$ Contrastenhanced CT remains the preferred modality due to its easy availability and lower cost, while still providing sufficient diagnostic and follow-up information. ${ }^{16}$ However, where there is concern for the possible presence of meningitisassociated focal or parenchymal complications, as in our case, most experts recommend contrast-enhanced MRI with DWI and FLAIR techniques, since it is superior in these conditions. ${ }^{17}$ It has been shown that MRI is more sensitive for early detection of focal inflammatory processes such as cerebritis-ventriculitis as well as for ruling out the presence of vascular brain involvement. ${ }^{18,19}$

Another interesting clinical aspect raised by this case is the role of C-reactive protein (CRP), an inflammatory marker discovered in 1930, and so called because of its reactivity with phosphocoline residues of $\mathrm{C}$-polysaccharide of Streptococcus pneumoniae, ${ }^{20}$ as a very useful and inexpensive test in the clinical decision-making process in patients with acute bacterial meningitis. Levels of CRP above $10 \mathrm{mg} / \mathrm{dL}$ are strongly associated with bacterial infections/sepsis, and levels above $20 \mathrm{mg} / \mathrm{dL}$ are good predictors of in-hospital 
complications (eg, need for mechanical ventilation), longer length of stay, and increased mortality. ${ }^{21,22}$ It is well-established that CRP is a very sensitive inflammatory marker that is synthesized in the liver and regulated by cytokines, with levels remaining stable in a patient across 24 hours reflecting the intensity of inflammatory response on a daily basis. ${ }^{23}$ This characteristic makes it a very good clinical tool for follow-up of the disease activity and its response to treatment. ${ }^{24}$ Its role in the diagnostic evaluation, treatment, and monitoring of therapy in bacterial meningitis is also well-established in all age groups. ${ }^{24-27}$ It is considered to be a more reliable marker of disease activity than either white blood cell count or erythrocyte sedimentation rate. ${ }^{28-30}$ In our case we found it particularly beneficial as an additional element for supporting the decision of when to consider repeating the brain imaging, as well as an indicator of therapeutic response.

\section{Conclusion}

Etanercept therapy has been linked in previous reports with increased risk of different types of invasive pyogenic infections, but this is the first report linking this medication with acute bacterial pneumococcal meningitis complicated with multiple brain abscesses. In the present case, we believe that the occurrence of this very rare complication, with no obvious risk factors for its development (eg, otitis, sinusitis, mastoiditis, on-going pneumonia, etc), was due to the immunosuppressive state caused by etanercept.

In patients with acute bacterial meningitis who are receiving anti-TNF- $\alpha$ therapy, the threshold for suspecting focal complications must remain low. These patients might benefit from close clinical observation, discretional brain imaging and, as in this case, daily serological inflammatory markers (ie, CRP levels). Also, in all cases of meningitis, a coordinated multidisciplinary approach is necessary in order to improve the outcome and reduce the possibility of long-term sequelae. Clinically silent post-pneumococcal meningitis neurological sequelae are not entirely uncommon. Finally we believe that severe pneumococcal meningitis complicated with brain abscesses should be considered for addition to the list of invasive pyogenic infections consequent to etanercept therapy.

\section{References}

1. Bazzoni F, Beutler B. The tumor necrosis factor ligand and receptor families. N Engl J Med 1996;334:1717-1725.

2. Tobinick EL, Gross H. Rapid improvement in verbal fluency and aphasia following perispinal etanercept in Alzheimer's disease. BMC Neurol 2008;8:27.

3. Tobinick E. Tumour necrosis factor modulation for treatment of Alzheimer's disease: rationale and current evidence. CNS Drugs 2009;23:713-725.

4. Tak PP, Kalden JR. Advances in rheumatology: new targeted therapeutics. Arthritis Res Ther 2011;13 Suppl 1:S5.

5. Bresnihan B, Cunnane G. Infection complications associated with the use of biologic agents. Rheum Dis Clin North Am 2003;29:185-202.

6. Ellerin T, Rubin RH, Weinblatt ME. Infections and anti-tumor necrosis factor alpha therapy. Arthritis Rheum 2003;48: 3013-3022.
7. Furst DE. The risk of infections with biological therapies for rheumatoid arthritis. Semin Arthritis Rheum 2010;39: 327-346.

8. Calin A, Dijkmans BA, Emery P, Hakala M, Kalden J, LeirisaloRepo M, Mola EM, Salvarani C, Sanmartí R, Sany J, Sibilia J, Sieper J, van der Linden S, Veys E, Appel AM, Fatenejad S. Outcomes of a multicentre randomised clinical trial of etanercept to treat ankylosing spondylitis. Ann Rheum Dis 2004;63:1594-1600.

9. Killingley B, Carpenter V, Flanagan K, Pasvol G. Pneumococcal meningitis and etanercept--chance or association? J Infect 2005;51:E49-E51.

10. Van de Beek D, de Gans J, Tunkel AR, Wijdicks EF. Community-acquired bacterial meningitis in adults. N Engl $\mathrm{J}$ Med 2006;354:44-53.

11. Weisfelt M, van de Beek D, Spanjaard L, Reitsma JB, de Gans J. Clinical features, complications, and outcome in adults with pneumococcal meningitis: a prospective case series. Lancet Neurol 2006;5:123-129.

12. van de Beek D, de Gans J, Spanjaard L, Weisfelt M, Reitsma JB, Vermeulen M. Clinical features and prognostic factors in adults with bacterial meningitis. N Engl J Med 2004;351:1849-1859.

13. Kastenbauer S, Pfister HW. Pneumococcal meningitis in adults: spectrum of complications and prognostic factors in a series of 87 cases. Brain 2003;126:1015-1025.

14. Hasbun R, Abrahams J, Jekel J, Quagliarello VJ. Computed tomography of the head before lumbar puncture in adults with suspected meningitis. N Engl J Med 2001;345: 1727-1733.

15. Weisfelt M, de Gans J, van der Poll T, van de Beek D. Pneumococcal meninigitis in adults: new approaches to management and prevention. Lancet Neurol 2006;5:332-342.

16. Carpenter J, Stapleton S, Holliman R. Retrospective analysis of 49 cases of brain abscess and review of the literature. Eur J Clin Microbiol Infect Dis 2007;26:1-11

17. Hughes DC, Raghavan A, Mordekar SR, Griffiths PD, Connolly DJ. Role of imaging in the diagnosis of acute bacterial meningitis and its complications. Postgrad Med J 2010;86:478-485.

18. Katchanov J, Siebert E, Endres M, Klingebiel R. Focal parenchymal lesions in community-acquired bacterial meningitis in adults: a clinico-radiological study. Neuroradiology 2009;51:723-729.

19. Jorens PG, Parizel PM, Demey HE, Smets K, Jadoul K, Verbeek MM, Wevers RA, Cras P. Meningoencephalitis caused by Streptococcus pneumoniae : a diagnostic ad therapeutic challenge. Diagnosis with diffusion-weighted MRI leading to treatment with corticosteroids. Neuroradiology 2005;47:758-764.

20. Keshet R, Boursi B, Maoz R, Shnell M, Guzner-Gur H. Diagnostic and prognostic significance of serum C-reactive protein levels in patients admitted to the department of medicine. Am J Med Sci 2009;337:248-255.

21. Kompoti M, Drimis S, Papadaki A, Kotsomytis K, Poulopoulou C, Gianneli D, Voutsinas D. Serum C-reactive protein at admission predicts in-hospital mortality in medical patients. Eur J Intern Med 2008;19:261-265.

22. Gabay C, Kushner I. Acute-phase proteins and other systemic responses to inflammation. N Engl J Med 1999;340:448-454.

23. Tillet WS, Francis T. Serological reactions in pneumonia with a non-protein somatic fraction of pneumococcus. J Exp Med 1930;52:561-571.

24. Peltola HO.C-reactive protein for rapid monitoring of infections of the central nervous system. Lancet 1982;1: 980-982.

25. Hansson LO, Axelsson G, Linné T, Aurelius E, Lindquist L. Serum C-reactive protein in the differential diagnosis of acute meningitis. Scand J Infect Dis 1993;25:625-630. 
26. de Beer FC, Kirsten GF, Gie RP, Beyers N, Strachan AF. Value of $\mathrm{C}$ reactive protein measurement in tuberculosis, bacterial, and viral meningitis. Arch Dis Child 1984;59:653-656.

27. Jereb M, Muzlovic I, Hojker S, Strle F. Predictive value of serum and cerebrospinal fluid procalcitonin levels for the diagnosis of bacterial meningitis. Infection 2001;29:209-212.

28. Hatherill M, Tibby SM, Sykes K, Turner C, Murdoch IA.

Diagnostic markers of infection: comparison of procalcitonin with $\mathrm{C}$ reactive protein and leucocyte count. Arch Dis Child 1999;81:417-421.

29. Bruns AH, J.J Oosterheert JJ, Hak E, Hoepelman AI. Usefulness of consecutive C-reactive protein measurements in follow-up of severe community-acquired pneumonia. Eur Respir J 2008;32:726-732.

30. Simon L, Gauvin F, Amre DK, Saint-Louis P, Lacroix J. Serum procalcitonin and C-reactive protein levels as markers of bacterial infection: a systematic review and meta-analysis. Clin Infect Dis 2004;39:206-217.

\section{Author Affiliations}

Yusuf Kasirye, $M D^{*}$; Narendranath Epperla, $M D^{\dagger}$;

Janaki Ram Manne, $M D^{+}$; Sowjanya Bapani, $M D^{+}$;

Romel J Garcia-Montilla, $M D, P h D^{+}$

*Department of Internal Medicine, Marshfield Clinic-Park Falls Center, Park Falls, WI USA

${ }^{\dagger}$ Department of Internal Medicine, Marshfield Clinic, Marshfield, WI USA 